\title{
Landscaper Working from a Raised Portable Work Platform Was Electrocuted When a Pole Saw Contacts Overhead Power Line - Massachusetts
}

Release Date: January 12, 2015

Investigation: \# 13-MA-019-01
Massachusetts Department of Public Health Occupational Health Surveillance Program

\section{SUMMARY}

On August 20, 2013, a 26-year-old male landscaper/foreman (victim) employed by a landscaping company was electrocuted while trimming tree branches from a portable work platform. The victim had been using a pole saw to trim the branches. At some point the top section of the pole saw came in contact with energized overhead power lines and the victim was electrocuted and then his clothes ignited. There were two co-workers on site at the time of the incident. They both heard a popping noise and noticed that the victim was being electrocuted. They went to the work platform and could feel the electric current so they got the work truck and used it to push the work platform away from the overhead power lines. At the same time, two different home owners placed calls for emergency medical services (EMS). EMS, the fire department and the local police arrived at the incident location within minutes. The work platform was lowered and the victim was transported to a med-flight helicopter and brought to a large regional trauma center where he died of his injuries later that day.

Contributing factors identified in this investigation included employees working within 10 feet of and coming in contact with energized overhead power lines, and that the company did not have an Injury and Illness Prevention Program (I2P2) and did not provide health and safety training.

The Massachusetts FACE Program concluded that to prevent similar occurrences in the future, employers should:

- Ensure employees remain at least 10 feet away from any energized power lines located on worksites and provide training about the hazards of power lines and appropriate personal protective equipment;

- Ensure that only "line-clearance tree trimmers" and power companies trim, access and maintain trees that are within 10 feet of energized overhead power lines; and

- Develop, implement, and enforce an Injury and Illness Prevention Program (I2P2) that addresses hazard recognition and avoidance of unsafe conditions.

In addition, home owners and property owners should:

- Contact power companies and/or "line-clearance tree trimmers" to maintain trees that are within 10 feet of energized power lines. 


\section{INTRODUCTION}

On August 20, 2013, the Massachusetts FACE Program was alerted by the local media that on the same day, a male landscaper was fatally injured while trimming branches from a work platform. An investigation was initiated. On November 19, 2013, the Massachusetts FACE Program Director traveled to the company's office location and met with the company owner to discuss the incident. The police report, death certificate, company information, and the OSHA fatality and catastrophe report were reviewed during the course of the investigation. In addition, the incident location was visited and photographed.

\section{EMPLOYER}

The employer, a custom landscape design-build company, had been in business for approximately 28 years at the time of the incident. Services provided by the company include designing, installing and maintaining lawns, plants, stonework, and drainage systems and snow and ice management. The number of company employees varies with the season. During the off season, the company has 12 full-time and three part-time employees. During the peak season, which includes August, the company has about 24 employees. The company owner is part of multiple industry trade associations. The company had workers' compensation insurance as required by law in Massachusetts (G.L. c. 152, Sec. 25A). Employees did not have union representation.

\section{WRITTEN SAFETY PROGRAMS AND TRAINING}

At the time of the incident, the company did not have an Illness and Injury Prevention Program (I2P2). The company held four safety meetings per year, which coincided with seasonal hiring. Safety meetings were held in April at the beginning of the season, May when hiring starts to pick up, June when students were hired for the summer, and in September at the end of the peak season when the company was getting ready for the colder weather tasks. The company provided employees with personal protective equipment, including gloves, hearing protection, and safety glasses. There was some on-the-job training for less experienced hires.

\section{VICTIM}

The victim was a 26-year-old landscaper/foreman who had been employed with the company for 10 years at the time of the incident. He was a graduate from a local agricultural high school and he held a current state-issued hoisting license. The day of the incident, a Monday, the victim arrived at the company office location at 7:30 a.m. and arrived to the job site at 8:00 a.m.

\section{INCIDENT LOCATION}

The incident occurred in a suburban residential neighborhood of single family homes. The owner of the house where the incident took place had hired the company to trim the trees that enclosed the property's side and backyards. Specifically, the scope of work was to trim branches that overhung the lawn and to raise the overall tree canopy. The house was located on a corner lot where two of the lot's property lines, the north and east property lines, abutted roadways. The northern property line that ran along the front of the house abutted a small dead-end roadway. The eastern property line that ran along the eastern side yard of the house, and was the location where the incident occurred, abutted a larger secondary roadway. Six large white pine trees growing in a line at the edge of the secondary roadway separated the roadway from the property's eastern side yard. This secondary roadway was 
asphalt and ran north and south where the incident occurred (Figure 1). There were no painted roadway markings on this roadway and traffic traveled both directions.

Multiple utility lines including cable, telephone and a 7,900 volt overhead power line ran along the east side of the secondary roadway. These lines transitioned to the west side of the roadway approximately $3 / 4$ of the way down the lot's eastern property line. The lines, including the overhead power line, then continued along the western side of the roadway and along the eastern edge of the property line where there was a utility pole (Figure 2).

\section{EQUIPMENT}

The equipment involved in the incident was a track mounted work platform manufactured in 2010 (Figure 3) that was being rented from a local equipment rental company. The work platform had an articulating boom, rubber tracks and four outriggers. Each outrigger extended approximately four feet. The overall dimensions with the platform and outriggers stowed were approximately four feet wide by six feet high by 13 feet long. The maximum platform height was approximately 34 feet with a maximum working height of 40 feet. The metal platform measured three feet seven inches by two feet two inches with a capacity of 500 pounds and was equipped with a metal guardrail. Fall protection, including a full body harness and a lanyard, was provided with the work platform by the rental company, although it was not being worn by the victim at the time of the incident. The lift had multiple warning decals from the manufacturer including a decal warning about the electrocution hazard when coming in contact or within close proximity of overhead power lines.

A hand saw and a gasoline powered pole saw were being used to trim tree branches. The pole saw being used was rented through an equipment rental company. The pole saw was eight feet long and had an 18 ounce gasoline tank located at the base of the pole along with the engine. Fully extended it appeared that the pole saw was about 10 feet long. The pole saw had multiple warning decals from the manufacturer including a decal warning about the electrocution hazard when coming in contact or within close proximity of overhead power lines.

\section{INVESTIGATION}

The job began the day before the incident and was estimated to take two days to complete. The company owner reported that the first day on the job site, he and the work crew walked around the property to review the tasks to be performed and any potential hazards, which included the observation of the overhead power lines. After this walk around, the company owner left the job site and the work crew, including the victim who was the foreman and two co-workers who were laborers, started the job.

The day of the incident, the victim arrived at the company office around 7:30 a.m. and then traveled to the job site arriving around 8:00 a.m. Shortly after the victim arrived at the job site the rest of the work crew, the two laborers, arrived at the job site. The work platform was already at the job site as it had been left overnight there from the day before.

Once at the job site the victim moved the work platform to the jobsite's eastern property line, positioning it between the row of pine trees and the roadway. The victim then started to prune the pine tree branches that faced the roadway from the raised work platform. The work platform was raised about 16 feet high. It was reported by the company owner that the scope of work did not include 
trimming this side of the trees. In addition, the company reported that as a company policy they don't trim branches around power lines and branches that face roadways.

When the co-workers arrived on site they started to clear branches that had already been pruned by the victim and that were on the ground. At some point the victim put the pole saw's base (motor and gasoline tank) on the platform's floor and the other end of the pole saw (blade) extended approximately two feet above and beyond the top of the platform's guard rail. Although not witnessed, around 9:15 a.m., while the victim was in the raised work platform and possibly repositioning the platform, the pole saw came in contact with the 7,900 volt energized overhead power line electrocuting the victim (Figure 4) and igniting his clothing.

One of the co-workers heard a loud popping sound and then noticed that the victim was being electrocuted and called to the other co-worker for help. As the two co-workers approached the work platform they could feel the electric current and they were concerned that the work platform was electrified. The co-workers then got the company truck and used the truck to push the work platform away from the overhead power lines.

At the same time two different home owners placed calls for emergency medical services (EMS). EMS, the fire department and the local police arrived at the incident location within minutes. The work platform was lowered and a fire extinguisher was use to put out the fire. The victim was transported to a med-flight helicopter and brought to a large regional trauma center where he died of his injuries later that day.

\section{CONTRIBUTING FACTORS}

Occupational injuries and fatalities are often the result of one or more contributing factors or key events in a larger sequence of events that ultimately result in the injury or fatality. The Massachusetts FACE team identified the following contributing factors in this incident.

- Working within 10 feet of energized overhead power lines without the proper personal protective equipment and tools

- No Injury and Illness Prevention Program (I2P2)

- Lack of adequate health and safety training being provided to employees

\section{CAUSE OF DEATH}

The medical examiner listed the cause of death as high voltage electrocution.

\section{RECOMMENDATIONS/DISCUSSION}

\section{Recommendation \#1: Employers should ensure employees remain at least 10 feet away from any energized power lines located on worksites and provide training about the hazards of power lines and appropriate personal protective equipment.}

Discussion: In this case, the victim was working from a raised aerial lift when the pole saw he had been using came in contact with energized overhead power lines. Neither the aerial lift bucket nor the pole saw being used was insulated. The employer reported that the scope of work for this job did not include trimming the side of the trees along the roadway edge and that the company had a no trimming policy for branches around power lines or that faced roadways. The employer also discussed 
performing a walk around the work site on the first day on that job to go over the scope of the task and any possible hazards, which included the observation of the power lines.

When overhead power lines are present on a job site, employers should inform all employees assigned to that work site about the power lines, remind employees to remain at least 10 feet away from any overhead power line, and provide insulated equipment, tools and gloves to employees. ${ }^{1,2}$

Information about the hazards of energized power lines should be part of a larger comprehensive Injury and Illness Prevention Program that addresses the full range of potential hazards employees are exposed to while at work (see Recommendation \#3).

\section{Recommendation \#2: Employers should ensure that only "line-clearance tree trimmers" and power companies trim, access and maintain trees that are within 10 feet of energized overhead power lines.}

Discussion: Any tree maintenance, including trimming, to take place within 10 feet of an energized power line must only be performed by a "line-clearance tree trimmer" as outlined by 29CFR1910.269 Electric Power Generation, Transmission, and Distribution. OSHA's definition of a line-clearance tree trimmer is: An employee who, through related training or on-the-job experience or both, is familiar with the special techniques and hazards involved in line-clearance tree trimming. ${ }^{3}$ All other employees performing tree work must stay at least 10 feet away from energized power lines at all times. ${ }^{1}$

The OSHA Electric Power eTool outlines that line-clearance tree trimmers must be able to: ${ }^{4}$

- Determine the voltage(s) of any lines that may pose a hazard before work begins.

- Ensure their body parts and any ladders, platforms, or aerial devices being used remain outside the minimum approach distance from any energized part.

- Use only insulated tools and equipment to remove branches and limbs that are in contact with, or are within the minimum approach distance of, energized parts.

- Not work during adverse weather conditions that make the work hazardous.

In addition to these specific operational requirements, line-clearance tree trimmers must also:

- Be trained and certified in, and observed (at least annually) to be complying with, safetyrelated work practices and procedures including emergency procedures.

- Be provided a job briefing before starting a job or if expected conditions change.

- Properly wear approved PPE, including fall protection equipment, when needed.

- Operate mechanical equipment (aerial lifts) as outlined in 29CFR1910.269.

While line-clearance tree trimmers can work alone, a second line-clearance tree trimmer must be within voice range of the first line-clearance tree trimmer if:

- The trimmer will approach within 10 feet of any conductor energized at more than 750 volts.

- Parts are energized at more than 750 volts and branches or limbs are being removed from within the minimum approach distance.

- Roping is necessary to remove branches or limbs from conductors or equipment. 


\section{Recommendation \#3: Employers should develop, implement, and enforce an Injury and Illness Prevention Program (I2P2) that addresses hazard recognition and avoidance of unsafe conditions.}

Discussion: An Injury and Illness Prevention Program (I2P2) should include the systematic identification, evaluation and prevention or control of general workplace hazards and the hazards of specific jobs and tasks. The major elements of an effective program are management leadership, worker participation, hazard identification and assessment, hazard prevention and control, education and training, and program evaluation and improvement. ${ }^{5,6}$ The program should also include an explanation of the worker's rights to protection in the workplace, outline safe work practices workers are expected to adhere to, specific safety protection for all tasks workers perform, how workers can identify and avoid hazards, and who workers should contact when safety and health issues or questions arise.

In this case, procedures as part of the Injury and Illness Prevention Program should be developed for job sites that have power lines and other electrical hazards present at work locations where tasks will take place. Procedures should include informing employees that power lines are present, the exact location of the power lines, that employees must stay at least 10 feet away from the power lines, and any tools and required personal protective equipment (PPE) needed to complete tasks. The program should also require that a hazard analysis is performed of any new processes, including new equipment, products and chemicals being used, and any situation where new hazards have the potential to arise. When determining potential hazards associated with equipment, the manufacturer operator's manual and the equipment's warning decals should be reviewed and incorporated into the Injury and Illness Prevention Program procedures.

Although not factors that contributed to this incident, two additional common hazards that should be addressed by landscape companies are:

- Silica. Sand and stone materials, such as granite and pavers, contain silica. When cutting and buffing stone materials, employees can inhale dust containing silica. Exposure to silica can increase the risk of lung cancer and causes the lung disease silicosis, which is an incurable, debilitating, and sometimes fatal disease. Employers should provide and ensure the use of engineering controls (exhaust ventilation, dust collection systems, water sprays) to eliminate or reduce the amount of silica in the air and train workers on silica hazards.

- Fall protection. Employees who are working from a height of at least four feet (six feet for construction-related work) and are exposed to a lower level, fall protection must be provided by employers and used by employees. Whenever work is being performed from a raised aerial lift, employees must be provided with and wear fall protection in the form of either a fall restraint system (recommended) or a fall arrest system.

When developing an Injury and Illness Prevention Program, employers should start by evaluating all tasks performed by employees for potential hazards and incorporate information about these identified hazards and their controls into the program. ${ }^{5}$ Employers should also use their employees' expertise throughout the program development process by seeking employee input. Once the program is developed, employers should continue to seek employees' input during the routine updating of the program. The program should be updated when safety concerns arise and when new equipment and new tasks are introduced into the workplace. 
Employers should ensure that they have fully and effectively implemented their Injury and Illness Prevention Program by routinely performing assessments of tasks and immediately addressing any observed unsafe conditions. As part of the program's implementation, training should be provided to all employees on the program's topics, and procedures, and should also include hazard recognition and the avoidance of unsafe conditions. All training provided to employees should be documented.

When the Injury and Illness Prevention Program (I2P2) is updated, employers should then provide additional training on the new and updated safety and health program topics. For more information about Injury and Illness Prevention Program visit the Occupational Safety and Health Administration (OSHA) I2P2 webpage at www.osha.gov/dsg/topics/safetyhealth/. Also attached to the end of this report is a copy of the OSHA I2P2 fact sheet.

The Massachusetts Department of Labor Standards (DLS) offers free consultation services to help small employers improve their safety and health programs, identify hazards, and train employees. DLS can be contacted at 978-242-1351. More information about DLS can be found on their Web site at www.mass.gov/dos/consult.

The Massachusetts Department of Industrial Accidents (DIA) has grants available for providing workplace health and safety training to employers and employees. Any company covered by the Massachusetts Workers' Compensation Insurance Law is eligible to apply for these grants. More information about these DIA grants can be found on their Web site at www.mass.gov/dia/safety.

\section{Recommendation \#4: Home owners and property owners should contact power companies and/or line-clearance tree trimmers to maintain trees that are within $\mathbf{1 0}$ feet of energized power lines.}

Discussion: Home owners who are looking to have trees maintained that are located on their land and within 10 feet of power lines should first contact the power company to see if it is the power company's responsibility to maintain the tree. If it is determined that it is not the power company's responsibility, then a line-clearance tree trimmer should be hired to complete the job. While the power company is on site, the property owner should inquire about the possibility of the power company turning off or shielding the power lines that are in within the work location.

\section{REFERENCES}

1. Code of Federal Regulations. 29 CFR 1910.333 Selection and use of work practices. Washington DC. U.S. Government Printing Office, Office of the Federal Register.

2. Code of Federal Regulations. 29 CFR 1910.335 Safeguards for personal protection. Washington DC. U.S. Government Printing Office, Office of the Federal Register.

3. Code of Federal Regulations. 29 CFR 1910.269 Electric Power Generation, Transmission, and Distribution. Washington DC. U.S. Government Printing Office, Office of the Federal Register.

4. DOL. OSHA. Electric Power eTool.

www.osha.gov/SLTC/etools/electric_power/overheadlinework_lineclearance.html 
5. DOL. OSHA. Injury and Illness Prevention Programs, Fact Sheet No. 3665. www.osha.gov/Publications/OSHA3665.pdf. Date accessed: September 5, 2013.

6. Code of Federal Regulations. 29 CFR 1910.332 Training. Washington DC. U.S. Government Printing Office, Office of the Federal Register.

Figure 1 - Large pine trees being trimmed at the time of the incident

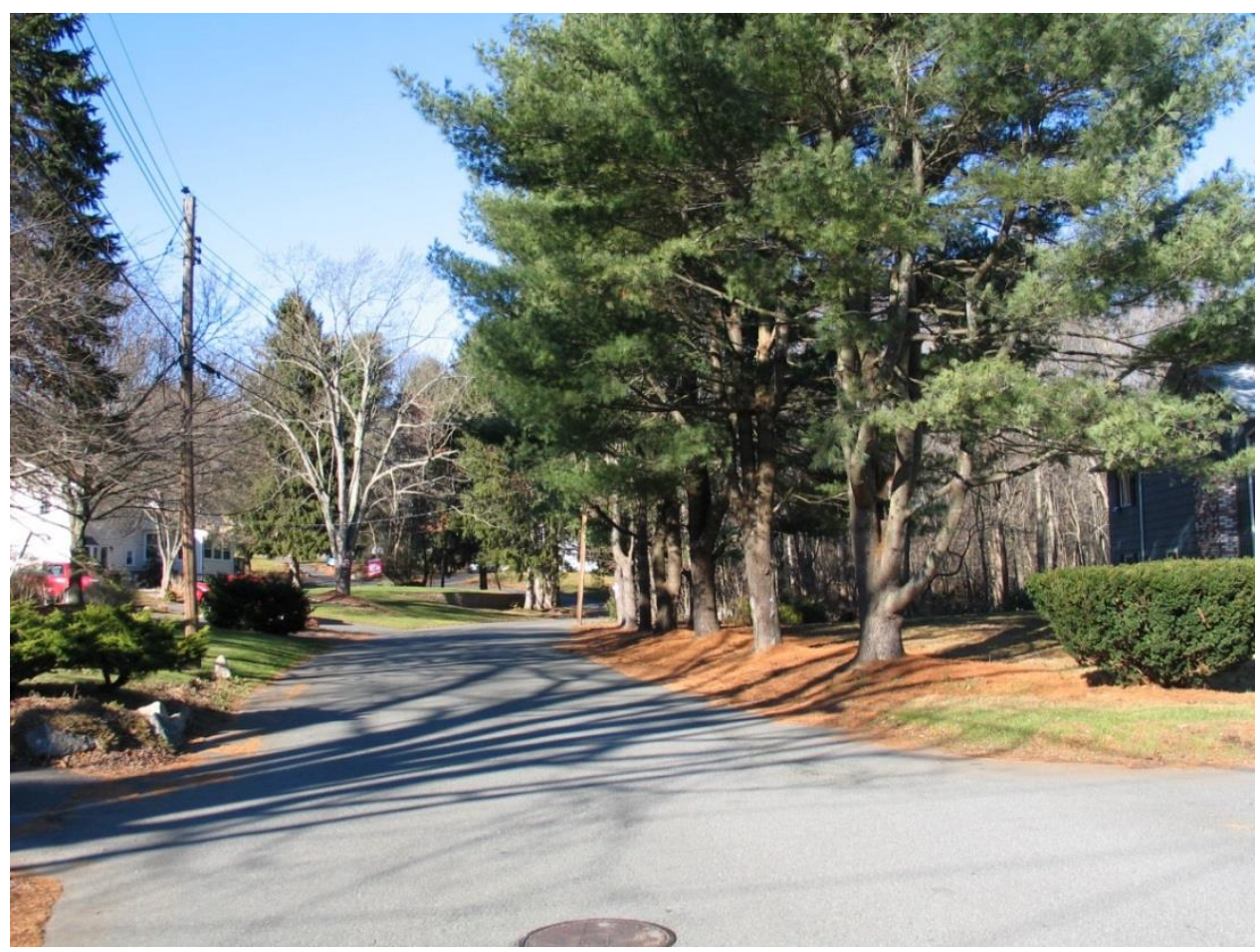


Figure 2 - Overhead power lines involved in the incident

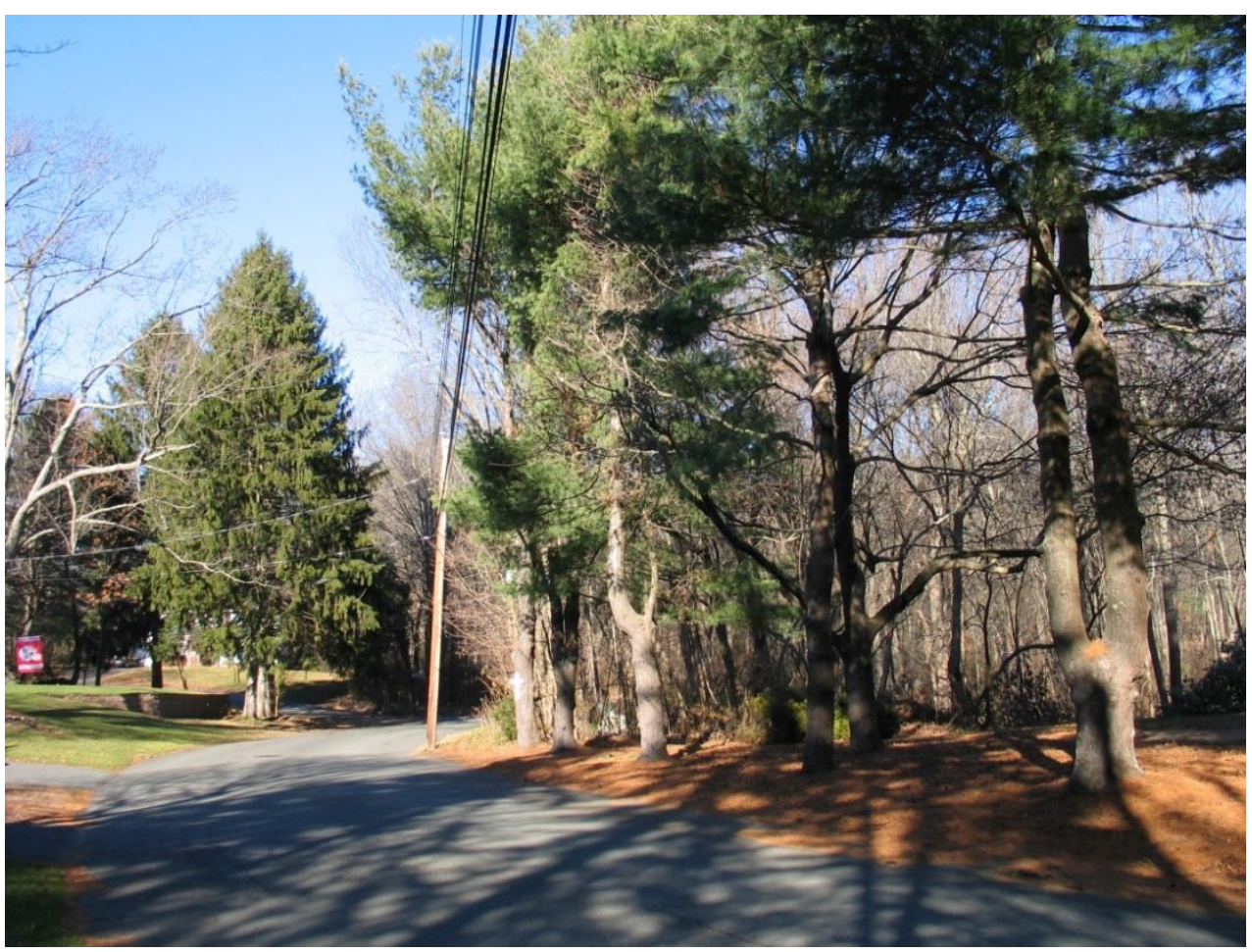

Figure 3 - Lift being used at the time of the incident

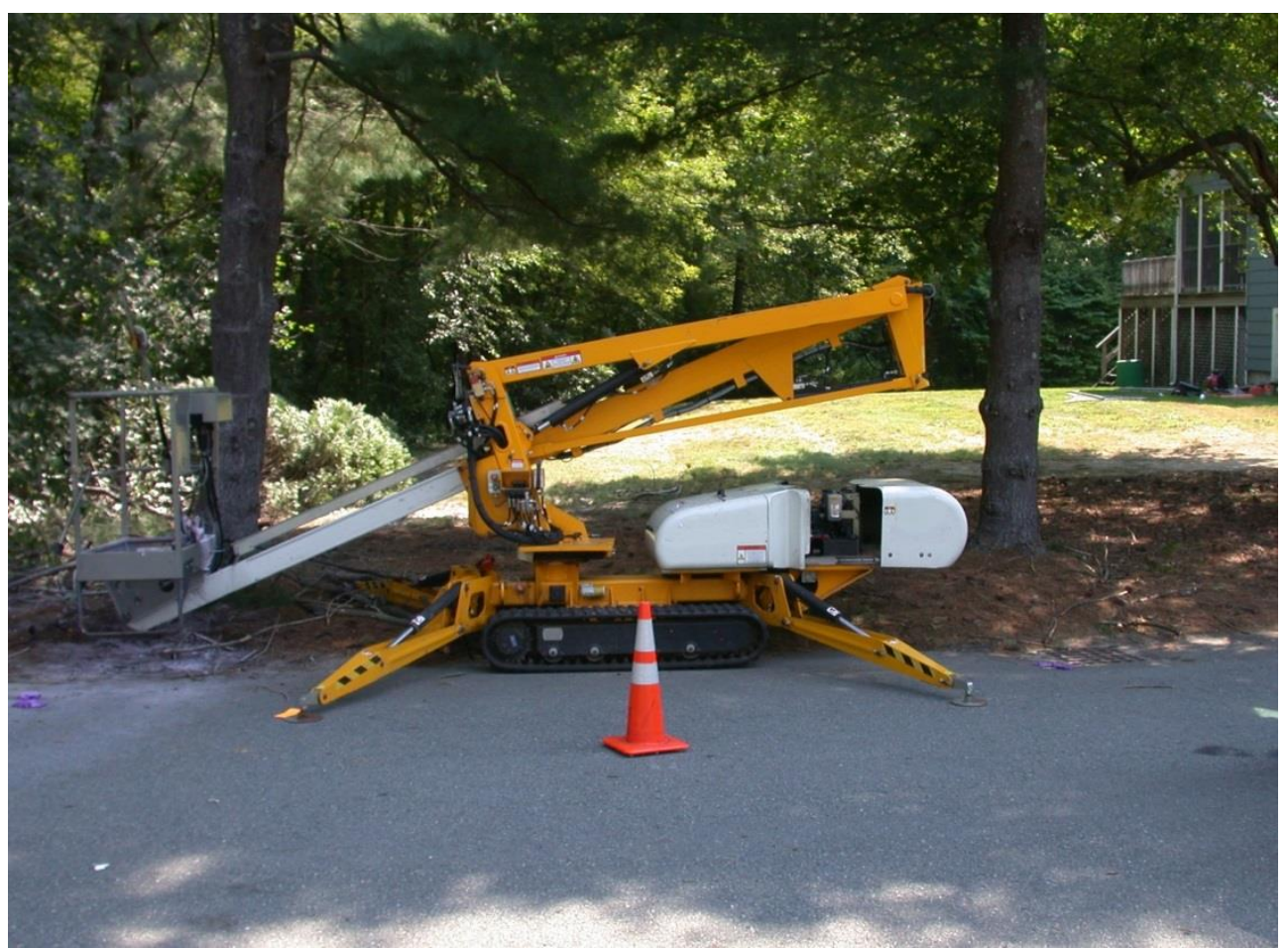


Figure 4 - Tree being trimmed at the time of the incident

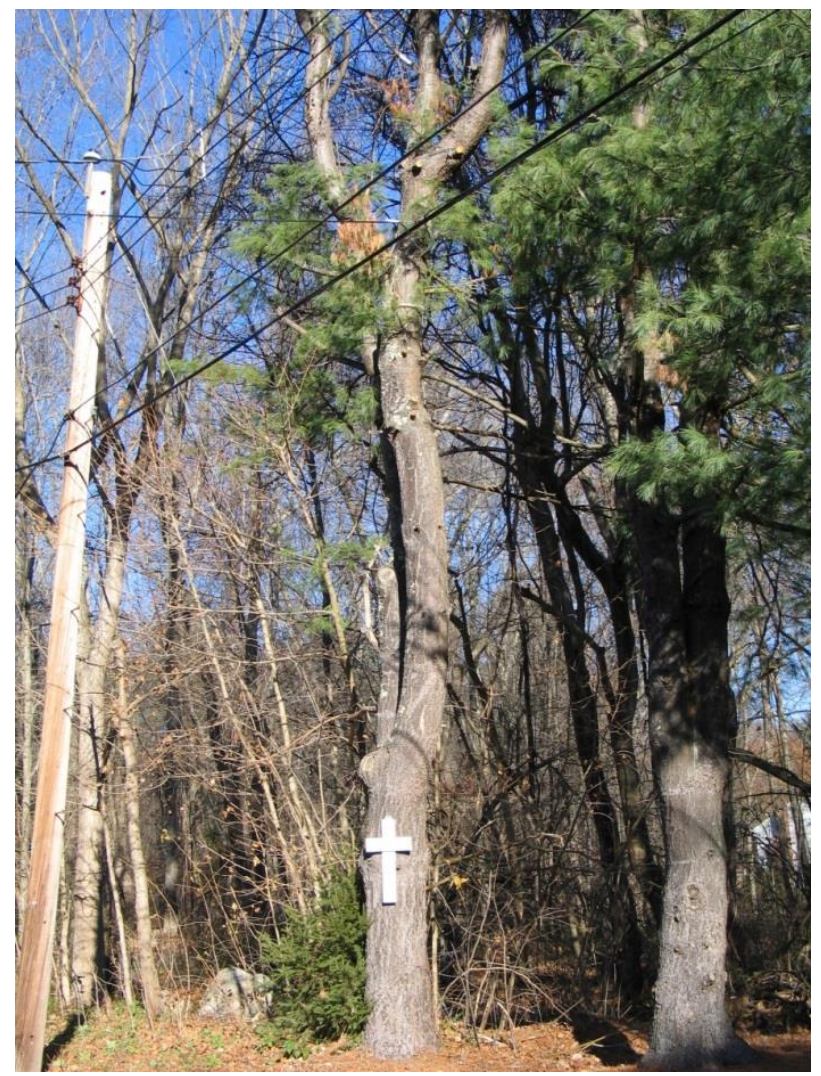




\section{OSHA FactSheet}

\section{Injury and IIIness Prevention Programs}

Injury and IIIness Prevention Programs are proactive processes that can substantially reduce the number and severity of workplace injuries and illnesses and can alleviate the associated financial burdens on U.S. workplaces. These systematic programs allow employers and workers to collaborate on an ongoing basis to find and fix workplace hazards before workers are hurt or become ill. This Fact Sheet describes some common program elements and how to implement them.

Injury and IIIness Prevention Programs are an effective tool for reducing occupational injuries, illnesses and fatalities. Many workplaces have already adopted such approaches, for example, as part of OSHA's Voluntary Protection Programs (VPP) and Safety and Health Achievement Recognition Program (SHARP) for small employers. Not only do these workplaces experience significant decreases in workplace injuries, but they often report a transformed workplace culture that can lead to higher productivity and quality, reduced turnover, reduced costs and greater worker satisfaction.

Thirty-four states and many nations around the world already require or encourage employers to implement similar programs. Based on the positive experience of these employers, OSHA believes that Injury and IIIness Prevention Programs can provide the foundation for breakthrough changes in the way employers and their workers identify and control hazards, leading to a significantly improved workplace health and safety environment. Adoption of an Injury and IIIness Prevention Program will result in workers suffering fewer injuries, illnesses and fatalities. In addition, employers will improve their compliance with existing standards and experience the financial benefits of a safer and healthier workplace.

Injury and IIIness Prevention Programs should include the systematic identification, evaluation and prevention or control of general workplace hazards and the hazards of specific jobs and tasks.
The major elements of an effective program include:

\section{Management Leadership}

- Establish clear safety and health goals for the program and define the actions needed to achieve those goals.

- Designate one or more individuals with overall responsibility for implementing and maintaining the program.

- Provide sufficient resources to ensure effective program implementation.

\section{Worker Participation}

- Consult with workers in developing and implementing the program and involve them in updating and evaluating the program.

- Include workers in workplace inspections and incident investigations.

- Encourage workers to report concerns, such as hazards, injuries, illnesses and near misses.

- Protect the rights of workers who participate in the program.

\section{Hazard Identification and Assessment}

- Identify, assess and document workplace hazards by soliciting input from workers, inspecting the workplace and reviewing available information on hazards.

- Investigate injuries and illnesses to identify hazards that may have caused them.

- Inform workers of the hazards in the workplace. 
Hazard Prevention and Control

- Establish and implement a plan to prioritize and control hazards identified in the workplace.

- Provide interim controls to protect workers from any hazards that cannot be controlled immediately.

- Verify that all control measures are implemented and are effective.

- Discuss the hazard control plan with affected workers.

\section{Education and Training}

- Provide education and training to workers in a language and vocabulary they can understand to ensure that they know:

- Procedures for reporting injuries, illnesses and safety and health concerns.

- How to recognize hazards.

- Ways to eliminate, control or reduce hazards.

- Elements of the program.

- How to participate in the program.

- Conduct refresher education and training programs periodically.
Program Evaluation and Improvement

- Conduct a periodic review of the program to determine if it has been implemented as designed and is making progress towards achieving its goals.

- Modify the program, as necessary, to correct deficiencies.

- Continuously look for ways to improve the program.

For more information, visit the Injury and IIIness Prevention Program page on OSHA's website at: www.osha.gov/dsg/topics/safetyhealth.

Twenty-seven states operate their own occupational safety and health programs approved by OSHA. States enforce similar standards that may have different or additional requirements. A list of state plans is available at www.osha.gov/dcsp/osp.

This OSHA fact sheet is available at: www.osha.gov/Publications/OSHA3665.pdf 